\title{
Cárcere da mente: algumas experiências de homens internados no hospital de alienados de Pernambuco no Estado Novo
}

\author{
Carlos Alberto Cunha Miranda*
}

\begin{abstract}
RESUMO
Muito se tem escrito sobre a História da Loucura e das Instituições Psiquiátricas, porém pouco são os estudos que tentam desvendar os labirintos da loucura, trazendo à tona - mesmo que sutis $e$ fragmentados - aspectos da vida dos considerados "loucos", apresentando dados sobre histórias de vida dentro e fora dos muros dos hospícios. Nosso objetivo é resgatar dados importantes sobre a história de alguns homens em situação de sofrimento psíquico, no período em que passaram pelo Pavilhão de Observação e, posteriormente, internados no Hospital de Alienados, espaço que não era apenas destinado à prática médica, mas que estava implantado em uma rede de poder e de saber no campo da psiquiatria institucional. São os prontuários que nos fornece pistas significativas para reconstituição da trajetória dos internos no Hospital de Alienados. Como fonte imprescindível, utilizamos alguns livros dos prontuários masculino correspondentes ao período do Estado Novo, marcado por posições autoritárias de seu interventor Agamenon Magalhães.
\end{abstract}

Palavras chave: Loucura. Prontuário. Estado Novo.

\section{Carcere of the mind: Some experiences of homes in the hospital de Alienados de Pernambuco in the Estado Novo}

\begin{abstract}
Much has been written about the History of Madness and Psychiatric Institutions, but there are few studies that attempt to unravel the labyrinths of madness, bringing to the surface - even if subtle and fragmented - aspects of the life of those considered "crazy", presenting story data of life inside and outside the walls of hospices. Our objective is to recover important data about the history of some men in situations of psychological distress, during the period they passed through the Observation Pavilion and, later, hospitalized in the Hospital of Alienated, space that was not only destined for medical practice, but which was implanted in a network of power and knowledge in the field of institutional psychiatry. It is the medical records that provide us with significant clues for reconstitution of the inmates' trajectory in the Alienated Hospital. As an indispensable source, we used some books from the male medical records corresponding to the Estado Novo period, marked by authoritarian positions of its interventor Agamenon Magalhães.
\end{abstract}

Keywords: Madness. Record. New State.

Artigo recebido em 30 jan. 2019.

Aprovado em 05 abr. 2019.

\footnotetext{
* Formado em Direito pela UFPE, com Pós-Graduação, Mestrado e Doutorado no PPGH da UFPE. Atualmente é Professor Associado II do Departamento de História da UFPE e trabalha com as temáticas de História da Saúde e das Doenças.
} 
Para a elaboração deste artigo, partimos da premissa de que a constituição do saber psiquiátrico não foi um atributo apenas de suas práticas entre os muros do hospício, mas também decorrente do contexto sociocultural e político em que o dito louco e seus familiares estavam inseridos no período do Estado Novo. Nosso objetivo é resgatar dados importantes sobre a história de alguns homens em situações de sofrimento psíquico no período em que passaram pelo Pavilhão de Observação e posteriormente internados no Hospital de Alienados, espaço que não era apenas destinado à prática médica, mas estava implantado em uma complexa rede de poder e saber no campo da psiquiatria institucional.

Como fonte imprescindível, utilizamos alguns livros dos prontuários masculinos correspondentes ao período do Estado Novo nos anos em estudo. Nesse sentido, buscamos uma nova abordagem historiográfica situada no campo de possibilidades históricas, através de vestígios e pistas sobre histórias de vida deixadas pelos pacientes, que contraria alguns trabalhos acadêmicos de inspiração foucaultiana, considerando seus excessos, a exemplo da supervalorização dos poderes institucionais sobre a loucura. Enfatizaremos pessoas e sua subjetividade, sem, contudo, desprezar as contribuições de Michel Foucault.

Os Prontuários do acervo do atual Hospital Ulysses Pernambucano, correspondentes aos anos de 1926-1960, é composto de 1.013 (mil e treze) volumes em papel, com média de cinquenta prontuários em cada um, que trazem no corpo teórico dados de práticas terapêuticas, histórias de vida e informações preciosas sobre a vivência do paciente no espaço asilar. Em relação aos Livros de Ocorrências não os encontramos no acervo. As informações do Livro de Registro eram incorporadas aos Prontuários. Nesses Prontuários, muitas vezes o diagnóstico era indefinido ou explicado como uma perturbação ou um comportamento que nada indicava uma "doença mental". No que tange ao aspecto do meio familiar, não eram necessariamente sinais de "loucura" os sintomas que promoviam o internamento, mas em muitos casos a conduta do paciente que incomodava seu meio familiar. Na leitura dos prontuários se percebe que homens, mulheres $e$ crianças foram internados pela polícia por indicação de seus familiares. Assim, todos os dias o carro da polícia estacionava na porta do Pavilhão de Observações trazendo dezenas de indivíduos recolhidos nas ruas ou encaminhados por suas famílias. Dentre eles, encontravam-se pessoas brancas, "pardas" e negras, com suposições de que eram epiléticas, maníaco-depressivas, histéricas esquizofrênicas, portadoras de demência precoce, alcoólatras, homossexuais, dentre outros possíveis diagnósticos. Posteriormente, aqueles que recebiam um diagnóstico conclusivo do seu estado mental eram internados no Hospital de Alienados. Apesar da aparente fragilidade dessa documentação, a historiadora Maria Clementina Pereira Cunha chama atenção para a 
importância das informações contidas nos Prontuários e seu valor como fonte histórica para aqueles que se debruçam sobre a história da loucura:

Por outro lado, empreender a análise a partir do hospício significa incorporar aí outras falas que se cruzam: apesar do esforço para aniquilar sua presença $e$ apagar sua voz, os registros do asilo denunciam a presença dos "loucos", resgatam ao menos em parte sua fala e sua experiência, evidenciam sua resistência surda e constante, permitindo o estabelecimento de relações para as quais os historiadores estiveram muito desatentos. Fazer emergir o arquivo de uma instituição psiquiatra equivale também a recuperar a dimensão de contraposição do poder absoluto da razão médica (Cunha, 1996, p. 16).

Os Prontuários, analisados em sua totalidade ou separadamente, ajudam-nos a conhecer as motivações dos internamentos, a visão dos pacientes acerca do seu próprio distúrbio mental, a lógica de funcionamento do hospício, os perfis dos internos, a relação entre os sintomas e normas sociais, as terapêuticas, os diagnósticos, as resistências, entre outros aspectos. Essa documentação era sistematizada da seguinte forma nos anos trinta e quarenta: na primeira página, dados pessoais como nome, cor, idade, filiação, estado civil, profissão instrução, naturalidade, residência, quem requereu a internação, falecimento, diagnóstico e fotografias de entrada e saída. Em seguida, eram analisados os antecedentes hereditários e colaterais do paciente submetido. Durante essa primeira fase de observação, eram colhidas informações sobre a possibilidade de algum de seus familiares, de primeiro ou segundo grau, serem portadores de alguma doença ou traços degenerativos (estado de alienação mental, epilepsia, criminalidade, alcoolismo, sífilis, tuberculose, etc.). Na próxima etapa, eram requeridos subsídios sobre os seus antecedentes sociais, momento em que os psiquiatras indagavam do dito louco sobre a sua vida em sociedade e se o mesmo havia contraído alguma doença na infância (sarampo, paludismo, catapora, coqueluche, etc.) ou em sua fase adulta. O número de filhos, os traumatismos, os acidentes, as "perversões sexuais" eram também motivos de questionamentos por parte dos médicos. No que refere ao "histórico atual da doença", eram apresentados os principais motivos da internação, aspecto interessante do prontuário em que podemos observar importantes informações fornecidas pelos pacientes, os quais, geralmente temerosos, expunham aos psiquiatras os motivos que os levaram à sua internação. Nessa fase do Prontuário, pode-se perceber pelos relatos dos pacientes que muitos daqueles que foram internados não apresentavam motivos graves para tal. Em muitos casos, a palavra da família junto aos médicos era, em última instância, o que determinava o seu destino na instituição asilar.

Logo após, eram procedidos os exames somáticos, através da utilização de métodos antropométricos, nos quais eram observados: altura, pelos, ossos, assimetria e possíveis anomalias. Aspectos da pele do rosto, cicatrizes, tatuagem, obesidade, digestão e da língua eram avaliados, 
além do fígado, coração, pulmão, da icterícia, sensibilidade objetiva e sensorial. Reflexos superficiais e profundos, perturbações na palavra, a exemplo da gagueira, eram minuciosamente examinados pelos psiquiatras. Posteriormente, passava-se para os exames neurológicos com a finalidade de identificar alterações na coordenação dos membros, exames da condição do olho, reflexos, fala, olfato e a forma de caminhar. Outros dados importantes registrados nos prontuários constavam no exame mental. Desde a entrada do paciente na sala, eram observados pelos médicos a sua postura, expressão facial, indiferença ou não do olhar, o humor, os gestos, a memória, a aparência e os hábitos higiênicos, conhecimento do espaço e do tempo, nível intelectual, atitudes de agressividade ou não durante o interrogatório e o seu comportamento nos primeiro dias de internamento. Percebemos na leitura dos prontuários que muitos pacientes se recusavam a falar durante o interrogatório, essa desobediência poderia significar uma reação à intimidação dos psiquiatras. Em alguns casos, era solicitado ao Instituto de Psicologia do Serviço de Higiene Mental dados sobre a Idade Mental, o QI.

Na etapa seguinte, constavam os exames complementares, ou seja, o resultado dos exames de urina, sangue, parasitológicos de fezes, dosagem de ureia e o exame de líquido céfaloraquiniano para detectar a sífilis. Esses requisitos nem sempre eram solicitados pelos médicos; nas páginas seguintes, seguiam-se a súmula, o diagnóstico e o tratamento. E, por último, o decurso, no qual eram apresentadas informações precisas sobre altas, novas internações e falecimentos. A causa mortis quase nunca era indicada nos prontuários. Ao consultar estes registros, percebemos que raramente ocorriam casos de "suspeitos de alienação" que não tivessem uma segunda ou mais internação. Verificamos ainda que, muitas vezes, os psiquiatras procuraram impor seus critérios médicos e morais para elaborarem diagnósticos e, dessa forma, por vezes, chegaram a denegrir a imagem das pessoas que se submetiam às suas observações.

Na leitura dos prontuários, percebe-se que não existe diálogo possível entre o psiquiatra do hospício e o interno: a fala do paciente serve apenas como "material clínico" que deve ser examinado para se chegar a um diagnóstico. Se o suspeito de loucura, por algum motivo, não cooperasse durante a anamnese, essa recusa era imediatamente considerada um grave sinal de "doença mental". Caso o paciente tentasse fazer algum comentário sobre o que julgava estar acontecendo, sua verbalização era quase sempre dada como "ininteligível". Em sua maioria, os psiquiatras demonstravam desinteresse pela opinião dos pacientes. Rotulado e isolado, restavalhe viver nos limites dos muros do hospício, sofrendo todo tipo de humilhação, violência $e$ sofrimento. Segundo Foucault, o interrogatório médico é uma maneira de substituir discretamente as informações tiradas do doente pela aparência de um jogo de significações que proporciona ao médico uma ascendência sobre o doente, podendo intervir, caso notasse que não estava dizendo 
a verdade, e mostrar que sabe mais do que ele. O interrogatório visa, igualmente, a produção de um dossiê permanente sobre o sujeito. Logo, estava à disposição do médico um sistema completo de anotações sobre o "doente" no hospício. Enfim, ele seria também o artífice do grande jogo da clínica, isto é, a apresentação do doente no interior de uma encenação na qual o interrogatório servia para a instrução dos estudantes e em que o médico atuava no duplo registro daquele que examinava e daquele que ensinava (Foucault, 2006). Essas linhas demostram o que ocorria no Pavilhão de Observações durante a anamnese do paciente.

A jornada na instituição representava uma ruptura com a vida anterior, na qual o interno podia realizar diferentes tarefas em lugares diversos e conviver com personalidades várias. $\mathrm{O}$ aspecto central das instituições totais, segundo Goffman, seria a eliminação das múltiplas esferas da vida, pois, a partir da internação, tudo o que envolvia a vida do paciente passava a ser realizado num mesmo local e sob uma única autoridade (Goffman, 2005). Cada fase da sua atividade diária seria realizada na companhia de um grupo grande de pessoas, com rigoroso controle de horário e sob a observação de enfermeiros.

O estudo desse período induz a análise das táticas desenvolvidas pelos pacientes para escarpar das imposições e do abuso da psiquiatria institucional. Essas formas de reações compunham o que Michel de Certeau denominou de antidisciplina (Certeau, 1994). No interior do Hospital de Alienados, astúcias foram registradas nos prontuários e nos escritos dos médicos na Revista Neurobiologia, criada em 1938 por Ulysses Pernambucano. Assim, as táticas dos pacientes eram as mais variadas possíveis: caminhar nu pelo pátio e enfermarias, não tomar a medicação prescrita, defecar e urinar em lugares que não fossem os sanitários, não comer, recusar o trabalho, chorar de forma convulsiva ou não, agredir outros pacientes e os enfermeiros, buscar o isolamento no leito ou pátio, demonstrar sua insatisfação pedindo aos médicos a todo o momento para ir embora para sua casa, usar roupas e enfeites que fugissem as vestimentas padronizadas, uso de "vocabulários pornográficos", gritar e cantar em voz alta, não responder as perguntas de médicos e enfermeiros. Para fugir do sofrimento imposto pelo sistema asilar, não foram poucas as tentativas de suicídio e de fuga no Hospital de Alienados. O namoro e as relações sexuais foram igualmente estratégias muito utilizadas pelos pacientes para reagir às vivencias amargas no interior do hospício.

Com a vitória da Revolução de outubro de 1930, ocorreram mudanças profundas na política institucional do país. Em Pernambuco, assume o poder como interventor o advogado Carlos de Lima Cavalcanti. Nesse período, a psiquiatria institucional põe em funcionamento novos modelos assistenciais que rompiam com as práticas dominantes de confinamento das pessoas consideradas loucas. Ambulatórios nos centros urbanos e colônias no interior foram criados com 
o objetivo de descentralizar as práticas de internação e desafogar os hospícios que se encontrava com suas populações muito acima de suas capacidades. Apesar do reconhecimento do Estado em patrocinar um modelo de assistência psiquiátrica diferenciada, o discurso sobre a doença mental continuou o mesmo, excluindo e destituindo as pessoas consideradas loucas da sua condição de cidadania.

Diante das precárias condições do Hospital de Alienados, Carlos de Lima resolve convocar, em 1931, Ulisses Pernambucano para criar a Divisão da Assistência a Psicopata de Pernambuco que resultou num programa de reforma no qual havia os seguintes órgãos: 1- Serviço para doentes mentais não alienados: a) Ambulatório e b) Hospital aberto; 2- Serviço para doentes mentais alienados: a) Hospital para doenças agudas; b) Colônia para doentes crônicos; 3-Manicômio Judiciário; 4- Serviço de Higiene Mental: a) Serviço de prevenção a doenças mental; b) Instituto de Psicologia (Marques de Sá, 1978).

Nesse período, Ulysses Pernambucano colocou em prática um modelo de assistência psiquiátrica já executado por Juliano Moreira no Rio de Janeiro e por Franco da Rocha em São Paulo. Esse modelo tinha como objetivo a reforma do Hospital de Alienados, a criação de colônias agrícolas e manicômios judiciários e a implantação de um amplo Programa de Higiene Mental. Tudo isso exigiu a ampliação de novas práticas terapêutica e preventiva cuja finalidade era investir, através de ações disciplinadoras, dentro e fora do hospício. Inicialmente, para resolver o grave problema da superlotação do Hospital de Alienados, foi construído um novo pavilhão destinado às mulheres, com capacidade para abrigar cento e quarenta leitos. Criou-se também um serviço de fotografia, através de um contrato com um profissional, em que o paciente era fotografado na entrada e na saída do hospital. Nas inúmeras fotografias observadas nos prontuários, percebe-se a imagem de um corpo rígido, constrangido e assustado. Com aparência triste, os olhos arregalados e os cabelos assanhados, o paciente era retratado de forma a comprometer a sua imagem. A partir dessa fotografia o paciente tinha sua identidade aprisionada por uma série de estigmas que dificilmente conseguiria se libertar. Apesar das reformas iniciadas por Ulysses Pernambucano, a situação do Hospital de Alienados nos primeiros anos da década de trinta era de extrema precariedade.

Com a incorporação do Instituto de Psicologia ao Serviço de Higiene Mental, iniciou-se uma série de pesquisas e investigações sobre crianças consideradas anormais, como também o estado mental dos adeptos da doutrina espírita e dos cultos das religiões africanas no Recife. Sentindo a necessidade de publicar o resultado de suas pesquisas, Ulisses Pernambucano encetou, em outubro de 1931, a publicação dos Arquivos da Assistência a Psicopatas de Pernambuco. Com o seu afastamento, em 1935, da direção geral da Assistência a Psicopatas, o periódico 
enfraqueceu, terminando por encerrar sua circulação. Ulisses foi ainda o responsável direto pela edição do Boletim de Higiene Mental e da Revista trimestral Neurobiologia lançada em junho de 1938.

Em 1932 é posto em prática o Serviço Aberto que permitiu aos pacientes serem assistidos inicialmente no ambulatório do hospital psiquiátrico e posteriormente no Hospital Correia Picanço. O serviço se dividia em duas partes: um ambulatório destinado aos pacientes que poderiam permanecer junto aos seus familiares e outro voltado para internação daqueles que precisavam de praticas terapêuticas especializadas, a exemplo da malariaterapia, e uma assistência médica imediata. Coube ao doutor Gildo Neto assumir a direção do serviço ambulatorial. Aos pacientes e seus familiares que frequentavam o SHM eram ministrados ensinamentos sobre como se deveria cuidar do paciente e os meios para combater a "doença mental". Um das principais preocupações dos psiquiatras responsáveis pelo ambulatório era com o alcoolismo, a sífilis e com o "baixo espiritismo". No ambulatório era realizada, sobretudo, uma pesquisa psicológica com o objetivo de confirmar os diagnósticos e de mensurar a inteligência através de testes psíquicos.

Devido à frequência com que os pacientes abandonavam o tratamento antes de receberem alta, a direção do ambulatório quase sempre recorreu ao Serviço de Higiene Mental para o reingresso das práticas terapêuticas. Ainda no ano de 1932, o governo adquiriu um terreno situado na Rua Padre Roma, onde seria instalado o futuro hospital aberto - Correia Picanço. Em maio de 1935, foi inaugurado o pavilhão anexo ao ambulatório, construído com donativos dos pacientes (Relatório da Assistência a Psicopatas de Pernambuco, 1935).

Nessa época, iniciaram-se no Recife os trabalhos "profiláticos" do Serviço de Higiene Mental. Suas atividades deveriam se enquadrar nos seguintes itens: I - Educação neuropsiquiátrica do grande público que está sendo feita através de conferências, artigos nos jornais e revistas, palestras pelo rádio, etc.; II - Combate às causas de doenças mentais diretamente acessíveis: álcool, sífilis, baixo espiritismo, etc.; III - Organização das estatísticas dos diferentes serviços, comentários e lições que delas se podem tirar sobre as psicopatias no nordeste; IV - Serviço social, assistência moral, científica e educativa, elas visitadoras do serviço, aos egressos dos nossos hospitais. Distribuição dos conselhos impressos sobre as causas mais frequentes de doenças mentais, modo de tratar o doente em família, etc.; V - Organização pelo Instituto de Psicologia de modelos de observação, perfil psicológico, etc. (Arquivo da Assistência a Psicopatas de Pernambuco, 1935, p. 47).

O Serviço era operacionalizado por monitoras, por um acadêmico interno mais bem classificado através de concurso - "auxiliar técnico de higiene mental" - e o Diretor. O crescimento das atividades do Serviço de Higiene Mental permitiu o surgimento, em 1933, da Liga de Higiene 
Mental de Pernambuco que seguiu uma orientação independente da Liga Brasileira de Higiene Mental (Boletim de Higiene Mental, 1935, p. 6). Entre outras atividades, a Liga promoveu inúmeras semanas antialcoólicas, conferências médicas em colégios, quartéis, teatros, além de palestra realizada semanalmente na Rádio Clube. Empenhou-se também em angariar recursos para construção de uma escola para crianças consideradas "anormais".

Nas visitas periódicas, realizadas pelas assistentes sociais e pelo auxiliar-técnico, eram atendidos e acompanhados os pacientes individualmente em suas residências e seus familiares recebiam regras de higiene mental. Sempre que fossem verificadas quaisquer anormalidades, as monitoras apresentavam ao médico assistente relatório sobre o estado do "doente" $e$ aconselhavam seus familiares sobre a melhor forma de lidar com ele. Era intenção dos dirigentes do Serviço que esses relatórios possibilitassem organizar as fichas dos pacientes, considerando especialmente os antecedentes, meio familiar e suas vivências em sociedade. Às monitoras cabia ainda convencer e reconduzir ao Ambulatório todos aqueles que abandonassem o tratamento. Para aqueles que residiam no interior, a diretoria do S.H.M. enviava cartas com instruções e conselhos. Inicialmente, o serviço de visita teve uma atuação tímida, entretanto, no ano de 1935 , verificou-se um notável aumento no número de visitações realizadas pelas assistentes sociais, tendo totalizado mil seiscentas e quarenta e uma visitas.

O cunho assistencialista e moralista desta política permitiu que os poderes públicos incrementassem a vigilância e o controle sobre as pessoas que apresentassem "comportamentos desviantes" na sociedade. Dessa forma, loucos de rua, mendigos, alcoólatras, homossexuais, prostitutas e "xangozeiros" muitas vezes foram encaminhados ao hospício e às prisões a fim de serem legitimados nestes lugares como "pessoas inferiores", tendo em vista a "preservação e o bem" da ordem social vigente. É importante ressaltar que, na época, a imensa população que passou a habitar os hospícios brasileiros foi obrigada a viver em condições degradantes, faltandolhes: espaços, verbas, roupas, enfermarias higienizadas, medicamentos eficientes, alimentação adequada e médicos. No início da década de trinta, o Hospital de Alienados de Pernambuco chegou a abrigar 1.128 pacientes, número considerado insuportável para um bom andamento de um hospital psiquiátrico. Com os hospitais repletos e a alta rotatividade de "doentes", muitos considerados degenerados e anormais, fazia-se necessário encontrar rapidamente a tão sonhada cura para a loucura, entretanto nos anos que se seguiram a situação não foi diferente.

Diante desta perspectiva, citamos uma importante observação de Michel Foucault, em sua obra Os Anormais, a respeito do discurso intervencionista dos psiquiatras que remonta ao início do século XX, quando a loucura se apresenta como tecnologia do anormal, dos estados anormais fixados hereditariamente pela genealogia do indivíduo (Focault, 2001, p. 402). Afirma Foucault 
que a psiquiatria "não visa mais, ou não visa mais essencialmente à cura [...] Ela se dá um papel de defesa social generalizada e, pela noção de hereditariedade, se dá ao mesmo tempo um direito de ingerência na sexualidade familiar. Ela se torna a ciência da proteção científica da sociedade, ela se torna a ciência da proteção biológica".

Com a eclosão do levante comunista de novembro de 1935, intelectuais e simpatizantes dos movimentos de esquerda do Recife passaram a sofrer violentas perseguições. No ano de 1934 , Agamenon Magalhães assumiu o Mistério do Trabalho, Indústria e Comércio, cuja gestão foi marcada por uma postura autoritária e anticomunista. Em 07 de janeiro de 1937, ocupou interinamente o cargo de ministro da Justiça e Negócios Interiores em substituição a Vicente Rao, tornando-se o segundo homem do governo Vargas. Nessa época, já comandava o Estado com mão de ferro e alinhado com os órgãos de segurança, especificamente o DOPS.

O Congresso Nacional aprovou o estado de sítio e, posteriormente, o estado de guerra que foi continuamente prorrogado a pedido de Getúlio Vargas até o golpe de 10 de novembro de 1937, que marcou a implantação do Estado Novo. Durante o governo autoritário implantado, o parlamento, as assembleias estaduais e as câmaras municipais foram fechados. Getúlio Vargas, que se manteve até 31 de outubro de 1945, passou a legislar através de decretos-lei e a intervir nos estados, confirmando ou nomeando interventores para os governos estaduais. Com as liberdades civis suspensas, o governo instituiu uma constituição Autoritária inspirada no nazifascismo europeu.

Nos primeiros anos do Estado novo foram instituídas medidas de caráter nacionalistas e de "uma maior valorização do homem brasileiro". Segundo Maria Luiza Tucci, Vargas, em seus propósitos nacionalistas, deu ênfase aos seguintes pontos: 1. Ideia de homogeneidade racial 2. Mitologia do trabalho como fonte de riqueza e ordem social 3. Execução de uma política demográfica colocada em prática através de restrições à imigração. Ainda segundo Maria Luiza, esse projeto se colocava contra os inimigos da pátria: as "raças inferiores" (incapazes de assegurar o progresso cultural); o "estrangeiro sem pátria" (inimigo externo); o "subversivo" (comunistas, anarquistas, bolchevistas, judeus); o "vagabundo", o "parasita" ou o malandro avesso ao trabalho. Nesse período, percebe-se que o pensamento autoritário da política estadonovista está recheado de tendências racistas. É nesse momento que o discurso eugênico ganhou cada vez mais espaço entre uma parcela da intelectualidade brasileira, imbuída desse novo espírito nacionalista (Carneiro, 1988). No decorrer desse trabalho, vamos apresentar as principais mudanças nos rumos políticos, bem como nas questões relacionadas à estrutura manicomial no Brasil através das ações de Adauto Botelho. 
Esse período retrata uma época em que se estabeleceu uma configuração diferenciada na política psiquiátrica assistencial brasileira. A partir de 1937, ocorreram reestruturações na assistência à saúde por parte do governo federal com a criação do Ministério da Educação e Saúde (MES) e da Divisão Nacional de Saúde (DNS). A essas instâncias de governo estava subordinada a Divisão de Assistência a Psicopatas (1927-1941) e, posteriormente, o Serviço Nacional de Doenças Mentais (SNDM), criado em 1941, responsável pela execução e uma significativa expansão da assistência psiquiátrica de abrangência nacional, organizando-a em termos de novas estruturas institucionais e de um aumento ao número de atendimento à população. Assim, o DNS expandia sua ação no campo da psiquiatria, até então mais centralizada no Distrito Federal (Venancio, 2010).

Com a instituição do SNDM, sob a administração do doutor Adauto Botelho (1941-1954), iniciou-se um processo de construção e ampliação de hospícios, além da fundação de novos ambulatórios. É importante ressaltar que as novas diretrizes tomadas pelos governantes continuaram nada favoráveis às pessoas internadas nos hospícios, especialmente aos hospitais psiquiátricos públicos, habitados em sua grande maioria por indigentes.

No dia 16 de junho, em passagem pela cidade do Recife, Botelho visitou o Serviço de Assistência a Psicopatas, as instalações do que seria posteriormente a Escola de Anormais, a Clínica Neurológica da Faculdade de Medicina, bem como outros estabelecimentos hospitalares. Três dias depois, foi homenageado no Clube Internacional do Recife pelos principais representantes das instituições médicas de Pernambuco. Na oportunidade, Ulysses Pernambucano realizou um veemente discurso, enaltecendo o trabalho desenvolvido por Juliano Moreira e pelo dirigente do SNDM, em prol da Higiene Mental no Brasil. Em seguida, teceu comentários sobre o êxito das terapias de choque na cura dos pacientes: as "doenças mentais psicóticas, aquelas nas quais parecia preponderar o fator individual, biótico, originariamente hereditário, influenciado por condições psicossociais das mais variadas - constituíam a nossa grande fraqueza". A terapêutica de Eletrochoque "pela Insulina e pelo Cardiazol marca inquestionavelmente", segundo os psiquiatras da época, "um progresso nesse domínio; ela restitui a sociedade uma elevada percentagem de doentes" (Neurobiologia, 1942, p.98). Na leitura sobre as Terapias Biológicas, constatamos que essa afirmativa não corresponde à realidade dos tratamentos nos hospícios (Miranda, 2014, p. 203 a 2019).

Logo após, Adauto Botelho exaltou o trabalho "titânico dos destemidos psiquiatras brasileiros que, de luta em luta, já se fizeram heróis de grandes vitórias (Neurobiologia, 1942), em favor da sociedade brasileira no campo da Higiene Mental e prometeu uma árdua campanha no Serviço Nacional de Doenças Mentais no sentido de concatenar dados e elementos, em o todo 
país, para instituições e pesquisas que possibilitassem auxiliar ainda mais a luta contra as "doenças mentais". Ainda com a palavra e utilizando um discurso marcadamente eugênico, convidou todos os participantes para uma grande "cruzada" tendo em vista um vigoroso combate contra o que chamou de "surto avassalador das psicopatias". Ciente de seu propósito de "guardião da família e da sociedade", Adauto clamou aos presentes para que serrassem fileiras nesta "batalha", com o propósito de semear "breves e compensadoras colheitas" (Neurobiologia, 1942).

Em Pernambuco, além da repressão violenta a qualquer manifestação contrária a nova ordem estabelecida, o interventor Agamenon Magalhães procurou incorporar diversos segmentos da sociedade para sustentação do seu comando: a maior parte da burguesia industrial $e$ latifundiária, uma parcela significativa da pequena burguesia urbana $e$ as forças armadas. Posteriormente, os coronéis se tornaram o principal sustentáculo político de seu governo. Nesta circunstância, procurou neutralizar e manipular setores da classe trabalhadora, através da captação de diversos sindicatos atrelando-os ao Ministério do Trabalho.

Neste ínterim, além da rígida censura contra a imprensa, foi desencadeada uma feroz perseguição, por parte da polícia política, aos comunistas e seus simpatizantes, progressistas e integralistas. Durante o período do Estado Novo, a polícia de Agamenon seguiu de perto Gilberto Freyre e outros intelectuais do cenário médico e político nacional. Ulysses Pernambucano, desde o início dos anos trinta, teve sua vida investigada pelo DOPS, em virtude de seus estudos a respeito da condição da vida da população rural de Pernambuco em que desenvolveu, junto ao Instituto de Psicologia, uma visão crítica em relação à oligarquia dos usineiros. Esse embate percorreu quase toda a década de 30 pelos jornais. Em 1935, algum tempo após o episódio do levante comunista, Ulysses foi preso, acusado de subversão, tendo passado 60 dias na Casa de Detenção do Recife. Em ato no 93, de 05 de janeiro de 1938, é destituído de sua cátedra no Ginásio Pernambucano. Julgado pelo Tribunal de Segurança Nacional - órgão criado pelo regime para julgar os acusados de subversão, foi inocentado no ano de 1940, por não ter sido provadas suas ações consideradas subversivas pelos órgãos de segurança. Apesar de ser absolvido, Agamenon, através de seus auxiliares do DOPS, vetou a sua reintegração na Faculdade de Medicina, nos termos da Carta Constitucional de 1937, que dispunha sobre o poder do governo, no "interesse do serviço público ou por conveniência do regime", de aposentar ou reformar funcionários civis ou militares. A partir daí, a repressão a Ulysses Pernambucano se tornou mais intensa, por influência direta de Agamenon Magalhães que o considerava uma ameaça à sua autoridade como Interventor. Ulysses foi perseguido até a sua morte, em 05 de dezembro de 1943, no Rio de Janeiro, vitimado por um infarto fulminante (Rocha, 2003). 
Os segmentos do governo de Agamenon ligados à segurança do Estado foram também ao encalço de grupos religiosos que não professavam o catolicismo, especialmente os espíritas e adeptos da religião afro-brasileira. Muito dos praticantes destes cultos, quando não eram presos, foram encaminhados, pelo órgão de segurança, ao Hospital de Alienados, sob a acusação de perturbarem a ordem pública e de praticarem o exercício ilegal da medicina. Ridicularizados, tornaram-se manchetes dos principais jornais do Recife, especialmente o governista Folha da Manhã.

É importante ressaltar que, ainda em 1932, foi realizado no Recife um acordo entre a Secretaria de Segurança Pública e o Serviço de Higiene Mental. Nessa época, o funcionamento dos terreiros e dos centros espíritas estava diretamente subordinado à autorização da polícia que, por muitas vezes, usava violência para fechar os locais de cultos e prender seus praticantes. Com o objetivo de aumentar as práticas de controle sobre as seitas existentes no Recife, Ulysses e seus principais colaboradores propuseram aos governantes uma solução conciliatória. O psiquiatra e seus assistentes submeteriam os praticantes do espiritismo e dos cultos africanos a um exame mental e a polícia, por sua vez, com o aval do S.H.M., comprometer-se-ia a permitir o funcionamento dos locais de culto, desde que fosse agendado o dia e a hora de sua realização. A ação normativa do Serviço de Higiene Mental assumiu um lugar de destaque quando o seu Boletim publicou os requisitos necessários para o desempenho dos Centros Espíritas e dos Terreiros dos cultos africanos: 1 . Exame Psiquiátrico completo do babalorixá ou médium do centro espírita; 2. Determinação da I.M. e Q.I. (escala Binet - Simon - Terman revisão pernambucana) e perfil psicológico de Rossolimo (adaptação pernambucana) feita pelo Instituto de Psicologia; 3. Entrega dos estatutos e regulamentação das seitas e dos centros espíritas, assim como a lista das funções; 4. Registro desses centros em livros especiais; 5. Compromisso de não se entregarem à prática ilegal da medicina e permitirem visitas de nossas auxiliares.

Após a concessão da licença, periodicamente os centros passavam a serem visitados pelas assistentes sociais e auxiliares técnicos que descreviam, através de um relatório bem circunstanciado, as cerimônias, os vocabulários utilizados, as toadas africanas e os fenômenos de transe. Dessa forma, os médiuns e os pais de santo passaram a ser submetidos a um exame mental para determinar o seu quociente intelectual e o perfil psicológico. Sempre que era possível o médico do Serviço de Higiene Mental procurava fazer o médium se manifestar e suas auxiliares taquigrafavam suas palavras. Em nome dos bons costumes e da saúde pública, o S.H.M. e não mais a polícia passou a exercer o controle e a fiscalização dos terreiros.

Durante o Estado Novo, com o objetivo de vigiar e reprimir todos aqueles que discordassem de suas posições autoritárias, o interventor nomeou o bacharel Etelvino Lins para 
Secretaria de Segurança Pública que, utilizando-se da força policial, realizou uma intensa repressão contra todos aqueles que fossem contrários à orientação política de Agamenon Magalhães. Os praticantes dos cultos afro-umbandistas também foram duramente controlados e perseguidos pelos membros da polícia, encabeçados principalmente pelo delegado João Roma, conhecido no meio policial como "o diabo louro". Essa referência a João Roma está presente em quase todos os periódicos da cidade do Recife.

No início de janeiro de 1938, os adeptos de Ulysses Pernambucano publicaram no Boletim de Higiene Mental um convite aos líderes das seitas para uma reunião com o objetivo de criar mecanismos para expurgar do Recife os terreiros considerados "impuros". A partir desse anúncio, as autoridades policiais fecharam um grande número de terreiros, rompendo o acordo com a Assistência aos Psicopatas. Durante sua ação repressiva, a polícia recolheu em caminhões uma quantidade significativa de material voltado para esse tipo de culto. A pedido dos membros do S.H.M o material foi depositado no Museu do Estado, onde foi catalogado para estudos posteriores.

Frente à "cruzada" contra os excluídos da sociedade, a população de internados no hospital não cessava de crescer. Quase que diariamente, policiais, a mando dos delegados da capital e do interior, despejavam nas portas do hospício grupos de "loucos de todos os gêneros", alcóolatras e pessoas que apresentavam comportamentos considerados desviantes. Nesse contexto, houve também situações em que a própria família, para livrar-se de algum dos seus membros que importunavam com acessos de "loucura", internava e muitas vezes os deixava ao abandono. No trabalho sobre a Paralisia Geral em Pernambuco, os doutores José Alberto Maia e Luiz Ataíde apresentaram importantes quadros estatísticos sobre a população de pacientes internada no Hospital de Alienados entre os anos de 1935 e 1946. Percebe-se na tabela um aumento expressivo no número de internos (Maia, 1948).

\begin{tabular}{cccc} 
ANOS & MASCULINO & FEMININO & TOTAL \\
\hline 1935 & 304 & 316 & 620 \\
1936 & 413 & 442 & 855 \\
1937 & 412 & 403 & 815 \\
1938 & 355 & 371 & 726 \\
\hline
\end{tabular}




\begin{tabular}{llll}
\hline 1939 & 420 & 408 & 828 \\
1940 & 478 & 411 & 889 \\
1941 & 447 & 418 & 865 \\
1942 & 397 & 381 & 778 \\
1943 & 417 & 356 & 773 \\
1944 & 474 & 474 & 948 \\
1945 & 539 & 447 & 986 \\
1946 & 592 & 790 & 1.382 \\
\hline TOTAL & 5.248 & 5.217 & 10.465
\end{tabular}

Frente a essa superlotação, a rotina do Hospital, apesar de novas formas terapêuticas serem anunciadas como curativas permaneceu a mesma e os chamados "loucos" continuaram a ser submetidos a ineficazes, degradantes e violentos tratamentos. Em seu cotidiano, os 'doentes mentais', incluindo menores de idade, foram obrigados a conviver com a superlotação, a falta de verbas e de vestuários, uma alimentação inadequada, medicamentos ineficientes, enfermarias sem higiene e pessoal técnico não qualificado. Para agravar ainda mais a situação do hospital que se encontrava com suas capacidades exauridas, pacientes foram internados junto àqueles que apresentavam doenças contagiosas, fato que acarretou sérios problemas de saúde, chegando até, em algumas situações, a ser fatal. Os casos mais graves eram encaminhados para o hospital Osvaldo Cruz, que posteriormente passou a recusar os pacientes portadores de doenças infectocontagiosas. Exauridos, os pacientes eram obrigados a dormir no chão frio das enfermarias, haja vista a insuficiência de leitos.

No momento das refeições, esse excessivo número de pacientes aguardava ansiosamente, nas longas e desorganizadas filas, a disputada bandeja contendo alimentos geralmente de péssima qualidade, ocasião em que eram vivenciadas situações vexatórias, grande apreensão e muita confusão. Diante dessa situação de perda de autonomia e humilhação, muitos foram tomados por um estado de apatia, apresentando-se de cabeça baixa, sem rumo pelos corredores e pátios do hospital ou buscando o isolamento no leito. Fragilizados, rapidamente entravam num processo de total aniquilamento de sua individualidade. Quando permaneciam por muito tempo internados 
no hospital, seja pelo abandono da família ou pelo agravamento da doença, eram vitimados por um quadro de cronificação irreversível (Miranda, 2010, p. 72).

Ocorreram casos em que pessoas foram internadas no hospício porque assumiram publicamente a sua homossexualidade, sendo considerados, na época, portadores de um comportamento pernicioso e responsável por manifestações de "patologias mentais". A exemplo de J. T. C., diagnosticado como portador de uma "personalidade psicotica onisoide e amoral com sexualidade anormal - Homossexualidade". Aos seus 23 anos de idade, avaliado como "doente mental", foi excluído do convívio social e internado através da polícia, no dia 29 de dezembro de 1938, como indigente. Solteiro, de cor branca, dizia-se católico, era alfabetizado e havia exercido a profissão de tecelão. Natural de Floresta dos Leões (terceiro distrito), residia no bairro da Torre. No decorrer dos exames realizados no Serviço de Observação, os psiquiatras observaram que o paciente assumia posições anarquistas: era tabagista e bebia com certa frequência. Em relação aos seus antecedentes sociais, foi ressaltado o fato de haver recebido uma educação "um tanto livre, passando os dias pelas ruas. Suas companhias eram as piores possíveis de modo que desde cedo se entregou aos mais torpes vícios, tornou-se pederasta passivo, etc. já havia frequentado centros espíritas com intuito de tratamento".

Em relação ao exame mental, consta no seu prontuário que respondia às perguntas de forma monossílaba, sem emoção e afirmava que gostava muito do que fazia. Narrou, logo no início do exame, que estava no Hospital porque praticou atos sexuais com conhecidos seus. Relatou ainda que teve várias vertigens, chegando a cair sem sentido, sem, contudo dar maiores explicações. Aparentando indiferença e calma, respondeu às questões que lhe eram perguntadas, "por vezes sem lógica". No final do exame, mudou subitamente de cadeira, explicando que assim o fizera porque sentiu "o guia cutucando ele".

No dia 13 de janeiro de 1938, recebeu alta. Durante o período em que esteve fora do hospício, foi procurado pela monitora do Serviço de Higiene Mental, Maria José Uchôa, a pedido do Dr. Jose Lucena, no dia 14 de janeiro de 1939. Em seu relato, a monitora faz uma detalhada descrição dos seus antecedentes hereditários e colaterais. Informou que o paciente frequentou a escola e era alfabetizado. De fácil amizade, gostava muito de "frequentar diversões" e tomar bebida alcoólica, sem o conhecimento da família. Sua genitora esclareceu que J. T. C., desde o ano de 1937, apresentava perturbações mentais e que ele vinha do interior com frequência ao Recife para trabalhar e quase sempre pedia demissão sem um motivo justificado. Contou que um dos seus irmãos era fiscal da Tranways e o colocou como condutor de bonde, mas no primeiro dia de trabalho J. T. C. se desentendeu com um colega, sendo expulso da companhia. A partir daí, tornou-se impaciente, pensativo e triste. Resolveu voltar a Paudalho onde residiam seus pais, lugar 
em que passou a trabalhar na agricultura. Na vivência familiar, certa vez J. T. C. se desentendeu com o pai que ameaçou de espanca-lo, ocasião em que J. T. C. se enfureceu e agrediu, com um banco, seu genitor. Por esse motivo, seus pais resolveram encaminha-lo ao Recife para a residência dos irmãos.

Em 21 de maio de 1940, deu entrada pela segunda vez, recebendo alta onze meses depois, a pedido da família. Durante esse período de internação foi feito o Exame de Liquido CéfaloRaquiniano, através da punção suboccipital, com resultado negativo. Esse exame consistia na retirada com uma agulha, através de uma punção do líquido localizado na espinha ou na região suboccipital. Na época, esse procedimento quando era realizado na região lombar, sem anestesia e com a introdução da uma grossa agulha, provocava fortes dores que poderia durar vários dias. Em geral, ela piorava na posição ereta e era aliviada quando a pessoa se deitava. Muitas vezes, quando atingia outras regiões da medula espinhal ou quando era retirada uma maior quantidade de líquor, os pacientes apresentavam paralisias parciais ou totais, provocando até mesmo a morte. Esse doloroso processo, em alguns casos, foi motivo de fuga de pacientes que não queriam ser submetidos a ele.

No final do mês de maio, a monitora Miriam Ludmer, atendendo à solicitação do Dr. Pedro Cavalcanti, procurou a família de J.T.C. para saber os motivos dessa sua internação. Na ocasião, seus familiares lhe disseram que J.T.C. desde sua alta do Hospital continuava praticando os mesmos atos que haviam motivado a sua internação. Costumava percorrer as ruas com trajes relaxados, sendo molestado pelas crianças da redondeza, apesar disso não revidava as provocações. Por vezes, não se alimentava e quase sempre estava triste, calado e chorava em alguns momentos. Apresentava alucinações, mas também momentos de perfeita lucidez. Diante dos conflitos constantes com seu pai, a família optou por sua internação no Hospital de Alienados.

Durante os meses de novembro e dezembro de 1940, J.T.C. sofreu vários choques através de injeções de Cardiazol. Essa terapêutica utilizada quase sempre seguia os seguintes procedimentos: após acomodar o paciente sobre um leito, sem travesseiro e em posição decúbito dorsal, colocava-se um pedaço de borracha entre os seus dentes para, em seguida, aplicar uma injeção de cardiazol o mais rápido possível. Caso a primeira dose não provocasse a crise convulsiva, acrescia-se mais $1 \mathrm{cc}$ da droga. Após a convulsão artificial, o doente deveria permanecer em repouso em ambiente silencioso. Durante a convulsão, a pessoa submetida apresentava violentas reações de espasmos. Inicialmente, permanecia com os membros do corpo imobilizados durante alguns segundos, posteriormente, com os olhos revirados, era tomado por grande agitação, na qual sacudia, violentamente, os braços e a pernas, além de movimentar freneticamente a cabeça de um lado para o outro. Da boca escumavam salivas, as quais, 
ocasionalmente, vinham misturadas com sangue em virtude da mordedura da língua e dos lábios. Nestes ataques, era frequente a involuntária ejeção de fezes e de urina pela co-participação espasmódica da musculatura abdominal. Além disso, ocorria uma fase agonizante com fortes sensações de medo, angústia e pavor, suas feições tornavam-se pálidas e a respiração difícil. Outras complicações geradas por este violento procedimento médico foram fraturas, luxações, acidentes dentários, complicações respiratórias e cardiovasculares, dores musculares, cefaléia, vômitos, náuseas, crises convulsivas espontâneas e trombose. Não é difícil para o leitor perceber o sofrimento de J.T.C. ao ser submetido por dois meses a essa terapia biológica.

No dia 4 de maio de 1941, J.T.C. foi novamente reconduzido ao Hospital de Alienados, tendo recebido alta três meses depois, novamente a pedido da família, sendo esta a última informação que consta em seu prontuário.

Nos anos 1930 e 1940, o corpo do homossexual foi definido no embate existente entre os saberes jurídico e médico. É o psiquiatra enquanto perito que vai dizer quem é o anormal na sociedade. Os médicos buscavam, através de suas produções científicas, assegurar sua autoridade ao se pronunciar sobre personalidades consideradas desviantes, afirmando o aspecto patológico do desejo homossexual. Nesse contexto, os postulados eugênicos das intervenções médicas não podem ser negligenciados, já que representaram uma estratégia que permitiu ampliar as fronteiras de controle da vida social. Os médicos defendiam que a homossexualidade não se tratava de um crime, pecado ou vício, mas de uma anormalidade que cabia à medicina curar. De acordo com James Green, em menos de duas décadas, a homossexualidade foi intensamente estudada, classificada e patologizada. Embora esse processo tenha se iniciado no final do século XIX, a consolidação do papel dos profissionais da psiquiatria e da medicina legal diante do Estado facilitou a "medicalização" do homossexual, no século XX. Esses profissionais venceram a queda de braço para decidir a quem pertencia a jurisdição sobre o assunto, embora tivessem que dividir a sua autoridade com a polícia e com o Estado (Green, 2000, p. 236-237). Assim, um dos tratamentos ou soluções encontrados foi o isolamento dos pacientes em instituições psiquiátricas, em meio às transformações profundas na estrutura política e social brasileira nas quatro primeiras décadas do século XX.

Depois de muitos debates, a homossexualidade como crime, no Código Penal de 1940, não foi aceita. O capítulo específico foi discutido e reforçado na lei do "atentado violento ao pudor" que poderia enquadrar as relações de mesmo sexo em certas situações, ou seja, como atos que causavam escândalo público e ofensa à moral e aos bons costumes.

Assim como o homossexualismo, o alcoolismo foi uma das tantas outras formas de classificação dos comportamentos considerados anormais que precisavam ser tratados nos 
hospícios. Por trás desses "desvios", havia histórias de vida explicadas por fragilidades econômica, social e política, mas que as teorias psiquiátricas, apoiadas na biologia, apontavam como tendo uma origem essencialmente comportamental. Entre os homens, o alcoolismo era uma causa considerável de internação. O consumo abusivo da bebida não era exclusivo de nenhuma camada social, entretanto eram entre as pessoas mais pobres da população que se observava o grande número de internações para tratamentos psiquiátricos. Os consumidores da bebida, muitas vezes desempregados, moradores dos mocambos do Recife ou de outras cidades, eram com frequência diagnosticados como degenerados.

Dando continuidade à análise dos prontuários no período do Estado Novo, pesquisamos um livro com 50 prontuários de homens dos meses de maio e junho de 1942 do Hospital de Alienados, no qual encontramos dados importantes sobre a vida dessas pessoas consideradas loucas. O primeiro ponto que nos chamou atenção foi a falta de informações mais detalhadas nos prontuários sobre os homens durante o período de internação, uma vez que, em artigo escrito sobre as mulheres hospitalizadas nos anos de 1930 (Miranda, 2016, p 56-82), fica evidente a grande curiosidade dos psiquiatras sobre o universo feminino, especialmente referente às questões da sexualidade. Na leitura dessa documentação, optamos por narrar casos de pessoas portadoras de alcoolismo e epilepsia.

No item referente à classe, quase $90 \%$ era formada por pacientes indigentes. Esse dado vem demostrar que a grande clientela dos hospitais psiquiátricos públicos era oriunda das camadas mais pobres da população $e$, consequentemente, mais vulneráveis às medidas coercitivas do aparelho estatal. Em relação à cor, o predomínio é a parda, num total de 36 pacientes, 8 eram brancos, 2 morenos e 1 de cor preta. Esses dados vão de encontro ao discurso propagado pelos médicos eugenistas das primeiras décadas do século $\mathrm{XX}$ de que os negros eram mais propensos à loucura.

No que se refere aos diagnósticos, o motivo das internações masculinas era muito variado, ao contrário ao das mulheres que, em sua grande maioria, eram internadas com diagnóstico de psicose maníaco-depressiva, chegando a percentual que muitas vezes beirava $50 \%$. No livro consultado, a maior incidência dos internamentos era a de portadores, segundo os psiquiatras, de Psicose auto-toxica (alcoolismo) com 6 casos, Esquizofrenia igualmente com 6, seguindo de Epilepsia também com 6 internos. Outros foram internados com os seguintes diagnósticos: psicose maníaco-depressiva 3 casos, debilidade mental, Paralisia Geral, Arteriosclerose Cerebral, Demência Senil, Psicose Infecciosa, Psicose de Involução e um caso de Idiotia. É importante ressaltar que os diagnósticos de degenerados já não aparecem no livro consultado. 
Examinando os prontuários, podemos constatar que os internos exerciam as mais variadas atividades laborais, sendo em sua maioria: serventes, operários, pedreiro, agricultores, verdureiro, lajoteiro, militares, pintor, negociante, alfaiate, sapateiro, estivador, funcionário público, carvoeiro e auxiliar de comércio.

Nos requerimentos de internamento, consta a participação da polícia, de familiares, através de pais, filhos, irmãos, sobrinho, cunhado, e também de amigo. As prefeituras de algumas cidades também encaminhavam os ditos loucos, além de instituições hospitalares como o Serviço do Pronto Socorro, o Hospital Militar, Hospital Pedro II e o Hospital de Santo Amaro. As esposas não têm participação nesse processo, o que não ocorria quando elas eram internadas. No que se refere à idade, em sua grande maioria, os internos tinham entre 20 e 45 anos. O livro conta ainda a presença de três menores, com idades de 13, 15 e 16 anos, e três idosos, com idade de 67, 70 e 75. Entre os 50 pacientes, apenas um era protestante, todos os outros se diziam católicos. Em relação ao grau de instrução, há a informação de que a maioria era analfabeta ou tinha instrução rudimentar e alguns poucos fizeram o primário.

Um dado nos chamou atenção: o número expressivo de falecimentos. Do total de 50 prontuários analisados, em 15 há a informação de óbito no hospital. Essa importante informação vem demostrar as péssimas condições a que estavam submetidos no hospital: falta de higiene, medicação ineficiente, superlotação das enfermarias, maus tratos, presenças de doenças infecto contagiosa entre os internos etc. Na maioria das vezes, a única chance de sair dos cemitérios dos vivos, como o escritor Lima Barreto denominava o hospício, era a morte.

Dessa forma, tendo em vista à quantidade de informações contida nesses prontuários, optamos por analisar os de dois pacientes com os diagnósticos de Epilepsia (menor de idade) e Alcoolismo que faleceram durante o período de sua internação. Entre os homens, grande parte dos internamentos era motivada por doenças venéreas e um número significativo encontrava-se hospitalizados devido à paralisia provocada pela heredo-sífilis.

Em alguns prontuários, encontramos pessoas alcoolistas que foram internadas no Hospital de Alienados, é o caso de P.M., de cor parda, casado, com instrução rudimentar e católico, tinha 48 anos de idade. Fora encaminhado pela polícia, deu entrada no Serviço de Observação em 22 de maio de 1942 e, posteriormente, foi transferido para o Hospital de Alienados, tendo falecido 8 dias após sua internação, com o diagnóstico de Psicose Auto-tóxica - Alcoolismo. Consta em seus Antecedentes Hereditários que seus pais faleceram de causa ignorada e não eram etilistas nem tabagistas. "Nega tara neuro-psicopatica". Em relação aos Antecedentes Pessoais, Sociais e o Histórico da Doença, nada consta, segundo o psiquiatra, devido seu estado de "confusão". Em seu Exame somático, foi informado que P.M. tem boa compleição, musculatura adiposa e pouco 
desenvolvida. Lesões aparentes na pele e mucosas visíveis. Dentes mal implantados e conservados. Em relação ao Exame Neurológico, sua marcha era estática e possível de todas as posições. As pupilas reagiam lentamente à luz. Em seu Exame Mental, P.M. não respondia às ordens e nem às perguntas. De acordo com o médico, tinha alucinações auditivas $e$ visuais $e$ mantinha uma conversação desconexa. Não recebeu nenhuma intervenção terapêutica. Durante o período de internação, foi submetido ao Exame de Liquido Céfalo-Raquiano, em posição dorsal, com resultado negativo de sífilis.

Os psiquiatras do Hospital de Alienados reafirmavam que o alcoolismo era uma doença que afetava e ameaçava a sociedade, entretanto não percebiam a dimensão das condições de desigualdade, miséria e exclusão social da maior parte da população de Pernambuco que contribuíam, efetivamente, para o consumo exagerado do álcool.

O paciente de nome J.S.S. 35 anos, de cor parda, viúvo, católico, analfabeto, trabalhava como jornaleiro e foi encaminhado pelo Hospital de Santo Amaro sem diagnóstico clínico (Prontuário do Hospital de Alienados, n 8447). Deu entrada no dia 19 de junho de 1942, com o diagnóstico de Psicose Autotoxica e faleceu sete dias depois de sua internação. Devido ao pouco tempo de sua internação, não consta sua fotografia de entrada. Em seu prontuário, nada foi escrito sobre Antecedentes Hereditários, Pessoais, Colaterais e Sociais. Em relação ao Histórico da Doença, foi informado pelo médico que João foi transferido do hospital por passar as noites falando alto na enfermaria e com um comportamento agressivo para com os outros doentes. Em seu Exame Somático foi declarado que era do tipo leptossomático. Apresentava um regular desenvolvimento da musculatura, descamamento da pele visíveis, língua sabugosa e dentes mal implantados. Em relação ao Exame Neurológico, João apresentava uma marcha normal, ausência do sinal de Romberg. Apresentava reflexos normais e suas pupilas reagiam regularmente à luz. Segundo o psiquiatra, encontrava-se desorientado no tempo e no meio, além de não responder as perguntas.

As crianças e os adolescentes internados no Hospital de Alienados também foram submetidos às imposições do sistema de confinamento. Oriundos das classes pobres e muitas vezes rejeitados pela própria família, eram obrigados a conviver com adultos, estando sujeitos a todas as formas de violência, tanto por parte dos enfermeiros como dos próprios pacientes. É o caso de A.S., de cor parda, com a idade de quinze anos, analfabeto, se dizia católico e solteiro, fora encaminhado pelo Posto de Barreiro, cidade onde residia. Deu entrada no dia 7 de junho de 1942, com o diagnóstico de Epilepsia. Segundo o psiquiatra, tendo em vista o seu estado confuso. Nenhuma informação foi colhida sobre seus antecedentes hereditários, pessoais e colaterais assim como os sociais. Essa ausência na fala de A.S., certamente se deve ao fato do mesmo ser um 
adolescente com um quadro grave de epilepsia e possivelmente tenha ficado assustado e confuso frente ao interrogatório do psiquiatra. Em relação ao histórico da doença, o doutor foi informado pelo enfermeiro que o menor teve vários ataques epiléticos durante o período de sua internação no hospital. No que consta ao exame somático, era do tipo Pícnico, musculatura adiposa pouco desenvolvida. Apresentava descolamento da pele e mucosas visíveis.

É importante ressaltar que a partir da hipótese de que a manifestação de determinadas enfermidades mentais estavam relacionadas a certas estruturas corporais, nos anos 20 , o alemão Ernest Kretschmer dividiu os indivíduos em três tipos básicos: o encorpado ou Pícnico, o astênico ou leptosomático e o muscular ou atléticom. O Pícnico, que na classificação italiana corresponderia ao modelo brevilíneo, caracterizava-se pelo corpo redondo e baixo, com cabeça/peito/abdomen largos, musculatura mole e uma fisionomia marcada por linhas largas e redondas, além de um nariz carnudo. Em relação ao Exame Neurológico, foi constatado que A.S. tinha marcha normal. Possíveis quase todos os estudos semiológicos psicopatológicos que correspondem aos sintomas e sinais de transtornos mentais. Pupilas reagindo normalmente à luz. No que diz respeito ao exame mental, conta que o paciente se apresentava calmo com uma fisionomia triste e indiferente. "Não responde as perguntas e é indiferente ao cumprimento de nossas ordens". Desorientado no tempo e no meio, se refere às vezes a alucinações. No seu prontuário não há indicação de nenhuma terapêutica prescrita nem de exames complementares. No Decurso, conta que faleceu às 23 horas do dia 6 de julho do mesmo ano. Não é preciso para o leitor dimensionar o sofrimento de A.S. diante de todos os infortúnios de sua passagem pelo Hospital de Alienados. Diversos acontecimentos negativos marcaram no hospital sua mente que certamente fragilizaram de forma significativa seu corpo.

Historicamente houve uma forte associação da epilepsia ao crime e à loucura, mesmo quando não havia um quadro psiquiátrico associado à doença. Muitos pacientes epilépticos no século XX foram internados em hospícios onde sofreram todo tipo de violência, especialmente através das terapias biológicas. Já no final do século XIX, a perspectiva de Afrânio Peixoto sobre o epiléptico era a de que este representava um tipo de indivíduo degenerado e teria sua organização continuamente pervertida, não havendo momentos em que pudesse agir integralmente de modo racional (Peixoto, 1898).

Nos anos vinte a epilepsia era considerada pelos médicos com uma "doença mental de fundo degenerativo, revelada por uma autointoxicação permanente e uma excitabilidade fácil dos centros corticais e medulares que promovem modificações fundamentais de caráter e descarga motoras, sensoriais, psíquicas ou viscerais, de insólita violência (crise ou ataques epiléticos)". Ainda segundo Afrânio Peixoto, os epiléticos eram dotados de estigmas físicos de degeneração e 
possuidores de um caráter "móvel, suspeito, desconfiados, dissimulados, irritável, impulsivo, egoísmo, duplicidade, teimosia, crueldade”. Estigmatizados, eram consideradas pessoas passivas de adotarem "manifestações de periculosidade". Afrânio Peixoto ressaltava que a justiça e a medicina deveriam ficar atentas às reações perigosas provocadas pela epilepsia, não somente com relação à pessoa portadora da "doença", mas também "de sua família e até da sociedade em geral" (Peixoto, 1926).

Não é difícil para o leitor dimensionar o sofrimento desses pacientes diante de todos os infortúnios vivenciados em suas passagens pelo Hospital de Alienados. Diversos acontecimentos negativos marcaram no hospital suas mentes e, certamente, fragilizaram de forma significativa seu corpo, levando muitos à morte. Documentar histórias escondidas nos porões dos hospícios nos permite tentar compreender as vozes desses excluídos que, durante muito tempo, foram silenciadas, suprimidas e exploradas. Felizmente, estudos e visões da nova historiografia brasileira têm contribuído de forma significativa para alargar os horizontes da pesquisa histórica e discutir questões fundamentais de alteridade. Dessa forma, embasados nas informações contidas nos prontuários, oferecemos aqui fragmentos da história de homens que passaram pelo Hospital de Alienados durante o Estado Novo.

\section{Referências}

CARNEIRO, Maria Luiza Tucci. O Anti-Semitismo na Era Vargas - Fantasmas de uma geração (1930-1945). São Paulo: Editora Brasiliense, 1988.

CERTEAU, Michel de. A invenção do Cotidiano 1: Artes de fazer. Petrópolis: Vozes, 1994.

CUNHA, Maria Clementina Pereira. O espelho do mundo - Juquery, a história de um asilo. Rio de Janeiro: Paz e Terra, 1996.

FOCAULT, Michel. Os Anormais: curso no Collège de France (1974-1975). São Paulo: Martins Fontes, 2001.

FOUCAULT, Michel. O poder psiquiátrico. São Paulo: Editora Martins Fontes, 2006.

GOFFMAN, Erving. Manicômios, prisões e conventos. São Paulo: Perspectiva, 2005.

GREEN, James Naylor. Além do carnavai. A homossexualidade masculina no Brasil do século XX. São Paulo: Editora UNESP, 2000. 
MAIA, José Alberto, ATAÍDE, Luiz. A Paralisia Geral em Pernambuco. Estudos Estatísticos. Revista Neurobiologia. Tomo XI, 1948.

MARQUES DE SÁ, J. Abertura do Ciclo de Estudos sobre Ulysses Pernambucano. Recife: Academia Pernambucana de Medicina, 1978.

MIRANDA, Carlos Alberto Cunha. Quando a Razão Começa Julgar a Loucura: a institucionalização do sistema manicomial em Pernambuco. Cadernos de História: Oficina de História - Ano VII, n.7, 2010. Recife: Ed. Universitária da UFPE.

MIRANDA, Carlos Alberto Cunha. Terapias biológicas e a prática da lobotomia nos hospitais psiquiátricos de Pernambuco na primeira metade do século XX, p. 203-219. Saeculum - Revista de História, n.31, jul.-dez. 2014.

MIRANDA, Carlos Alberto Cunha. "Delírios Femininos": vivências de mulheres internadas no hospital de alienados (Recife/PE, 1927-1936). In: Dossiê História e Tecnologias de Saúde. Mneme - Revista de Humanidade, volume 17. no 38, Rio Grande do Norte, 2016.

PEIXOTO, Afrânio. Epilepsia e crime. Salvador: Oliveira e Companhia. Tese apresentada à Faculdade de Medicina da Bahia, 1898.

PEIXOTO, Afranio. Psico-patologia Forense. Rio de Janeiro: Francisco Alves, 1926.

ROCHA, Edyna Cavalcanti da. Ulysses: um Pernambucano. Recife: o Autor, 2003. Dissertação de Mestrado do PPGH da UFPE, CFCH, História, 2003.

VENANCIO, Ana Tereza Acatauassú; CASSÍLIA, Janis Alexandra Pereira. Política Assistencial psiquiátrica e o caso da Colônia Juliano Moreira: exclusão e vida social (1940-1954). In: WADI, Yonissa Marmitt; SANTOS, Nádia Maria Weber (orgs). História e loucura: saberes, práticas e narrativas. Uberlândia: EDUFU, 2010. 